\title{
4 \\ Reconstituting Polity in the Postpalatial Bronze Age
}

\begin{abstract}
In ancient times, the Greeks and those of the barbarians living near the sea, on the mainland or in the islands, when they began to find their way to one another by sea, turned to piracy. The men leading them were not unpowerful, seeking profit for themselves and providing for their poorer followers.

—THUCYDIDES, HISTORY OF THE PELOPONNESIAN WAR 1.5.1
\end{abstract}

The disintegration of palatial civilizations in the Aegean, Anatolia, the Levant, and Egypt has inspired reams of scholarship and explanations that range from climate change to seafaring marauders to systems collapse. Generic characterizations of the past by later historians like Thucydides have often been taken as references to specific time periods or events, especially when it comes to major societal transitions. This is problematic at best, but may still reflect some general concerns or characteristics of past groups. In focusing principally on collapse, much scholarship has (1) elided the transformative character of other societal developments that took place in a variety of locations and (2) overlooked the substantial continuities that can be traced to the Palatial period and even before. For example, the "Sea Peoples," who are mentioned in an inscription of Rameses III at Medinet Habu, have generated a large literature that assigns them many different roles (e.g., Oren 2000; Cline 2014; Cline and O'Connor 2003; Hitchcock and Maeir 2016; Fischer and Bürge 2017). Such groups, which were never presented in ancient sources as unified or as having a common set of goals or behaviors, have too often been essentialized as either consequence of or cause for Late Bronze Age upheavals. Yet at the same time they cannot be dismissed entirely, since this period does show a general pattern of increased maritime mobility. Such large-scale developments in the eastern Mediterranean must be seen alongside local and regional shifts in settlement and production that took place in the Greek landscape.

In this chapter I first show how Mycenaean settlement networks were reorganized in the absence of palaces, both topologically and geographically. Some regions changed much more than others, depending especially on the mode of 
political organization present in the Palatial period. Diachronically, we can see that smaller-scale, regionally distributed societies, such as those in Attica, Thessaly, and the Euboean Gulf, were less susceptible to collapse than highly centralized palatial systems of Boeotia, which had also experienced the greatest growth in Palatial times. Second, I examine the changing pottery and metal production networks that articulate connections between communities and regions, especially in terms of their reorganization in the face of new modes of sociopolitical organization and an age of mobility. Finally, I argue that shifts in settlement in central Greece also reflect developments in the wider Mediterranean world at the end of the second millennium BCE—namely, an increasingly maritime orientation, a widespread decentralization of political organization, and a bourgeoning age of mobility.

\section{PERSPECTIVES ON COLLAPSE}

Monocausal notions of collapse are outdated and largely debunked (see, e.g., Dickinson 2010, 484; Knapp and Manning 2016; Middleton 2017a, 2020). Eisenstadt $(1988,242)$ notes that "ancient states and civilizations do not collapse at all, if by collapse is meant the complete end to those political systems and civilizational frameworks." Comparative perspectives on the collapse of complex societies largely follow Eisenstadt, demonstrating strong elements of continuity and change in case studies from post-collapse Teothihuacan, the Terminal Classic Maya, preInka Peru, the Khmer Empire and its relationship to Angkor, and Rapa Nui (Easter Island), as well as from the Mycenaean palaces and their contemporaries in the Late Bronze Age Mediterranean (Middleton 2017a). Comparative perspectives reveal rather a need to focus on transformation, resilience, complexity, and historical context. ${ }^{1}$

The Mycenaean palaces came to an end somewhat suddenly and conclusively around the beginning of the twelfth century BCE. While this is often termed an abrupt collapse across a wide geographical area, it should rather be seen as a process that played out over at least several decades. In archaeological terms, however, this looks like a relatively rapid series of events. I suggest this series included: (1) an (over)extension of state authority as a result of palaces taking on monumental defensive building projects in the face of tension between Mycenaean polities; (2) the culmination of such tension in armed conflict; and (3) a rejection of palatial authority by those living under it, as evidenced through the total disappearance of Linear B, palatial architecture, and other accoutrements of centralized administrative hierarchy ( see also Jung 2016 on class struggle, war, and "old" and "new" political orders). This palatial collapse occurred only in palatial areas but its effects were

1. For further perspectives on collapse, especially as a comparative phenomenon, see, for example, Tainter 1988; Yoffee and Cowgill 1988; Redman 2005; Schwartz and Nichols 2006; McAnany and Yoffee 2010; Butzer and Endfield 2012; Faulseit 2016; Knapp and Manning 2016; Cunningham and Driessen 2017; Middleton 2017a, 2017b, 2018; Knodell 2018. 
felt throughout mainland Greece, restructuring the nature of polity, interaction, and social relations throughout the macroregion-albeit in widely disparate ways.

Palace destructions at Orchomenos, Gla, and Thebes may be the direct or partial result of conflicts between two polities represented by these three centers. The proximity of Thebes and Orchomenos would have been a source of tension between these two polities. This fits with the archaeological record of destructions at both sites, and it may be reflected in later literary traditions. The fortification of Gla drastically changed the relationship between the Orchomenian and Theban polities. Palaces in the Argolid also pursued major fortification programs in $\mathrm{LH}$ IIIB (Hope Simpson and Hagel 2006). We might term this an architecture of paranoia or an arms race in the face of mounting interpolity tensions. The subsequent destructions at the end of LH IIIB may have been the direct result of such tensions.

Not all palatial and palace-connected sites were destroyed at the end of LH IIIB, and several were reoccupied after a hiatus. Both Thebes and Eleon, for example, have significant occupation until LH IIIC Middle, when other centers in their vicinity start to thrive (Aravantinos et al. 2016a, 319; Van Damme 2017b, 349-50). It is important, however, that this marks the end of the palaces per se. While later occupation and building occur, specifically palatial architecture, art, and burial come to an end, along with any traces of central administration (Linear B). And while these events need not be attributed to interpolity conflict, they do represent a rejection of the palatial system, which we can interpret as a collective response to dissatisfaction with state authority in Boeotia.

Thessaly may reveal a less outright rejection of palatial systems. This may also suggest a less highly centralized nature of palatial authority. Dimini, Pefkakia, and Kastro Volos all continued to be occupied in LH IIIC Early, though only Volos endured after this period. Certain palatial aspects of material culture, most notably burial customs in the form of (diminutive) tholoi, persisted well into the Early Iron Age.

Athens, too, bears little evidence of destruction, and has a strong LH IIIC occupation. The archaeological record at Athens, however, is obscured by later building, so it does not demonstrate direct evidence of centralized authority. It is therefore impossible to tell whether it was purposefully destroyed and rejected. Broneer $(1948,1956)$ turned to historical sources describing a Dorian invasion that largely bypassed Athens to explain the combination of architectural elaboration (cyclopean fortifications, elaborate gates, secret springs) and lack of destruction. Dorians aside, such an idea may reflect some distant memory that Athens did not witness the same type of collapse that other polities did (though see also Van Damme, forthcoming, for another perspective).

The end of the Palatial period seems to have played out quite differently in different areas. Boeotia is perhaps the only region that fits a "standard" narrative of collapse, but even its situation must be viewed as complex, and understood as involving both interpolity conflict and a popular rejection of the palatial system. Otherwise one would expect that the distinctly palatial practices described above 
would have survived. This regionally specific overthrow, collapse, or however we wish to describe it, is reflected also in the fact that it is precisely the regions that did not host palaces that came to thrive in Postpalatial times.

While there is no denying that the Mycenaean palaces disappeared around 1200 BCE, this change should not be seen as the end of one society or culture and the beginning of another. The Mycenaean world endured, even if the palatial political system did not, with elements of continuity visible into the Early Iron Age and long after. As Murray $(2017,16)$ points out, scholars have long debated "whether we should see the transition from the Greek Bronze Age to the Iron Age as a story of disruption, stagnation, and reinvention or as a continuous and unified spectrum of development." This oft-invoked dualism of "continuity or change" is better replaced with a more inclusive framework. There are naturally elements of both.

\section{RECONSTITUTING SOCIETIES \\ IN THE POSTPALATIAL LANDSCAPE}

The Postpalatial settlement pattern in the Aegean is typically seen in terms of contraction, decline, and population movement (Dickinson 2006, 58-67). Quantitative aspects of economic decline are documented as well, and they may be linked to demographic change (Murray 2017, 210-48). Hope Simpson and Dickinson (1979, maps 4 and 5) catalog only about 30 sites that date to this period in the regions surrounding the Euboean Gulf, in contrast to over 150 from the preceding LH IIIA2-B Palatial period. A more recent count (Crielaard 2006, 275) puts the number of LH IIIC sites much higher, at over 50, although there is still a significant drop from the preceding period. In an earlier study I included 64 LH IIIC sites in the Euboean Gulf area (Knodell 2013). If we look to the archaeological record of Greece as a whole (the mainland and Crete, excluding the islands); the number of total "sites" goes from 1366 to 655, a 52 percent decrease (Murray 2017, 141). For central Greece in the accounting of the present study we go from about 276 sites in the Palatial period to 152 in the Postpalatial period, which is a 44 percent decrease (map 14). The shift in number of communities is also a 44 percent decrease, going from 190 to 114 (see table 6; see discussion in chapter 2 for distinctions between sites, findspots, communities, etc.).

These numbers look quite different when parsed by region (see figure 2). In Boeotia there is a dramatic decrease in site numbers from 66 to 20 (70 percent), which is what we might expect with the collapse of a social system resulting in population drop or dispersal, or certain types of sites no longer being necessary. In Euboea, however, the drop is less, going from 32 to 16. In East Lokris, we go from 27 to 17 . Attica is similar, going from 57 to 36 . Thessaly goes from 38 to 21 . Malis drops from 18 to 10. Phokis is the most resilient (a diachronic trend in this study), dropping from 28 to 21 . From the simple metric of site numbers, then, it appears that Boeotia was much more dramatically affected by the palatial collapse than other parts of central Greece, which makes good sense since it seems to 
have been the most centralized and "palatial" part of the wider region. Thessaly and Attica were less affected, perhaps having had palatial systems of some kind, but more dispersed regional political landscapes. Nonpalatial regions (Euboea, East Lokris, Phokis, Malis) seem to have been affected least, especially considering that many of the Palatial Bronze Age sites that do not show signs of later occupation were mere findspots. An analogy for variable response to palatial collapse might be found in the Peloponnese, where Galaty and colleagues (2015) have attributed the depopulation of Messenia to the collapse of a single state at Pylos while noting substantial continuity in the Argolid, particularly at Tiryns after the fall of Mycenae. A case for further comparison can be found in Achaia, which had no palace and experienced a great deal of continuity into LH IIIC (Arena 2015). In addition to the change in numbers of sites, there is a dramatic shift in location as communities-prominent ones especially-move toward the sea. This can be seen in both the settlement hierarchy and in modeled networks of interaction (map 15).

If we examine the sites that flourish in the aftermath of the palatial decline, they are particularly the ones in the densest clusters of modeled interaction: Lefkandi in central Euboea, Kynos in East Lokris, Perati in Attica-all of which seem to have been located in zones outside of palatial control (see chapter 3 ). It should come as no surprise that places that never made the transition to palatial life experienced continuity - or even thrived-following the palatial collapse.

Four characteristics of the settlement pattern in central Greece during this transition stand out immediately (see maps 14 and 15):

1. There is a significant decline in the number of sites found on the fertile agricultural plains that formed the center of the settlement pattern and hierarchy in the Palatial period.

2. More sites (proportionately), including nearly all of the largest and bestconnected centers, are located on or very near the coast.

3. LH IIIB pottery is found at nearly all sites where LH IIIC pottery is found, marking significant continuity.

4. The most significant sites and regions of the Postpalatial Bronze Age emerge in previously nonpalatial areas (i.e., in eastern Attica, Euboea, and East Lokris).

In this section I examine the reorganization of settlement patterns in Postpalatial times. I then turn to the archaeological evidence for the reconstitution of political authority that occurs at the end of the Late Bronze Age.

\section{Settlement Reorganization}

The palatial centers at Thebes, Orchomenos, and Gla left something of a vacuum when they abruptly came to an end. While Thebes and Orchomenos were occupied in the Postpalatial period, habitation there seems to have been on a smaller scale 
and there is no evidence for the sort of centralized administration seen before. This change is also borne out in the settlement pattern of the surrounding area. In the Palatial period, the exploitation of large agricultural plains was highly systematized. Palaces depended on extracting resources from the plains themselves, as well as the subsidiary centers, sites, and individuals within and around these plains. These smaller sites on the main plains (the Theban Plain and Kopaic Basin) were widely abandoned in the Postpalatial period (see map 14).

Eleon and Thebes maintained substantial populations throughout the Postpalatial period, although they look very different from the way they did in Palatial times. Continuity in occupation is demonstrated at Thebes by settlement evidence and through the continued use of tombs, signaling that at least some portion of the population stayed after the collapse of the palatial system (Tzavella-Evjen 2014, 63). Eleon exhibits strong influence from Thebes in LH IIIC Early, although it had already shifted its orientation toward the coast. Network changes in LH IIIC Middle, when interaction between coastal sites seems to intensify, began to exclude Eleon (Thomatos 2006; Van Damme 2017a). Nevertheless, Eleon demonstrates remarkable resilience throughout LH IIIC at the level of the household (Van Damme 2017b, 350; see also Small 1998).

Eutresis, on the other hand, is occupied only at the beginning of LH IIIC Early, suggesting that its population soon moved elsewhere, perhaps closer to the sea. Inland sites, when they do remain occupied, seem to have done so on account of their strategic locations and defensibility, rather than through the maintenance of relations with Thebes, which of course was preeminent in the previous period. This suggests (1) that the status of Thebes at the center of a regional settlement hierarchy was no longer relevant, and (2) that the agricultural and interregional connections facilitated by these sites did not remain important in their own right. In the Palatial period, settlements at Eutresis, Plataia, and Erythrai were strategically positioned on major land routes and in proximity to important agricultural areas. Kreusis was an important port on the Corinthian Gulf, which would have facilitated connections to the Peloponnese, western Greece, and perhaps the central Mediterranean. Mycenaean-built road remains on the mountain pass linking Kreusis and Eutresis demonstrate an infrastructural connection between these sites in the Palatial period (Heurtley 1925). Roads require substantial investment of organized labor, and in this case were almost certainly linked to a palatial authority. The shift in settlement pattern seems to signal the Postpalatial obsolescence of this connection between a secondary center of Thebes (Eutresis) and the sea (Kreusis).

The shift is even more dramatic in the former territory of Orchomenos. Gla, Chorsiai, and the network of fortifications around the Kopais was abandoned (see map 14). The cutoff in occupation at these strategic locations suggests that such places and the connections they offered were no longer seen as a priority for people in Postpalatial times. The overwhelming move in settlement toward the 


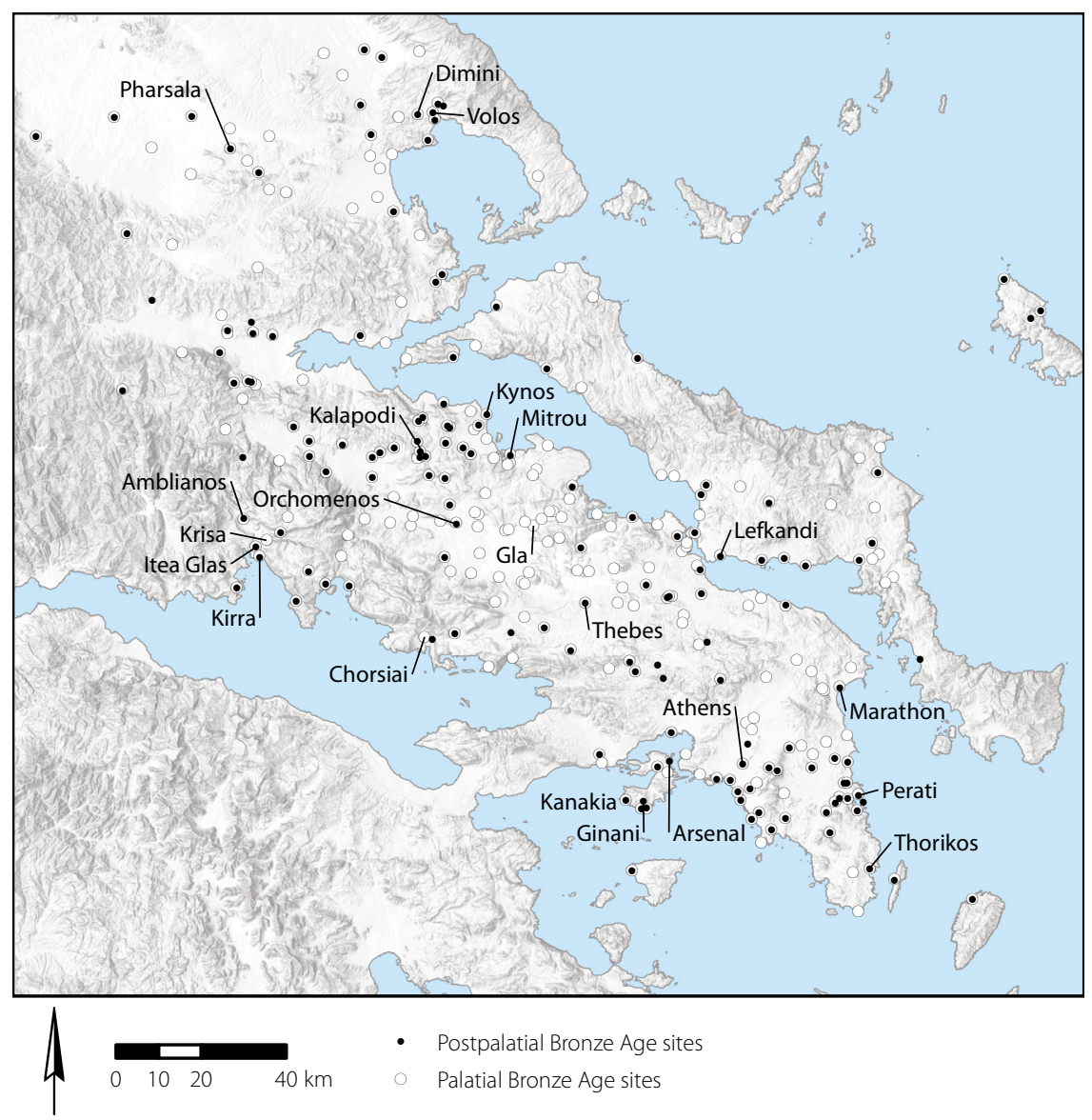

MAP 14. Postpalatial Bronze Age site locations compared to the Palatial Bronze Age.

sea, especially toward the Euboean Gulf but also in the direction of the Corinthian and Saronic Gulfs, suggests that connections and maritime resources were being actively sought between reconstituted communities. With palatial influence gone from maritime routes, these coastal zones provided new opportunities for enterprising individuals and communities to thrive. In this way, the coastscape reemerged as an important political space, after palatial interests had been oriented more inland toward agricultural plains. ${ }^{2}$ Indeed, that very domination of inland plains in earlier times may have pushed certain people out into more marginal, coastal zones with poorer land, establishing communities that eventually would be well positioned to pursue new subsistence strategies following the palatial collapse.

2. See Tartaron (2013, 9-11) on coastscapes, specifically with respect to the Early Mycenaean period. 


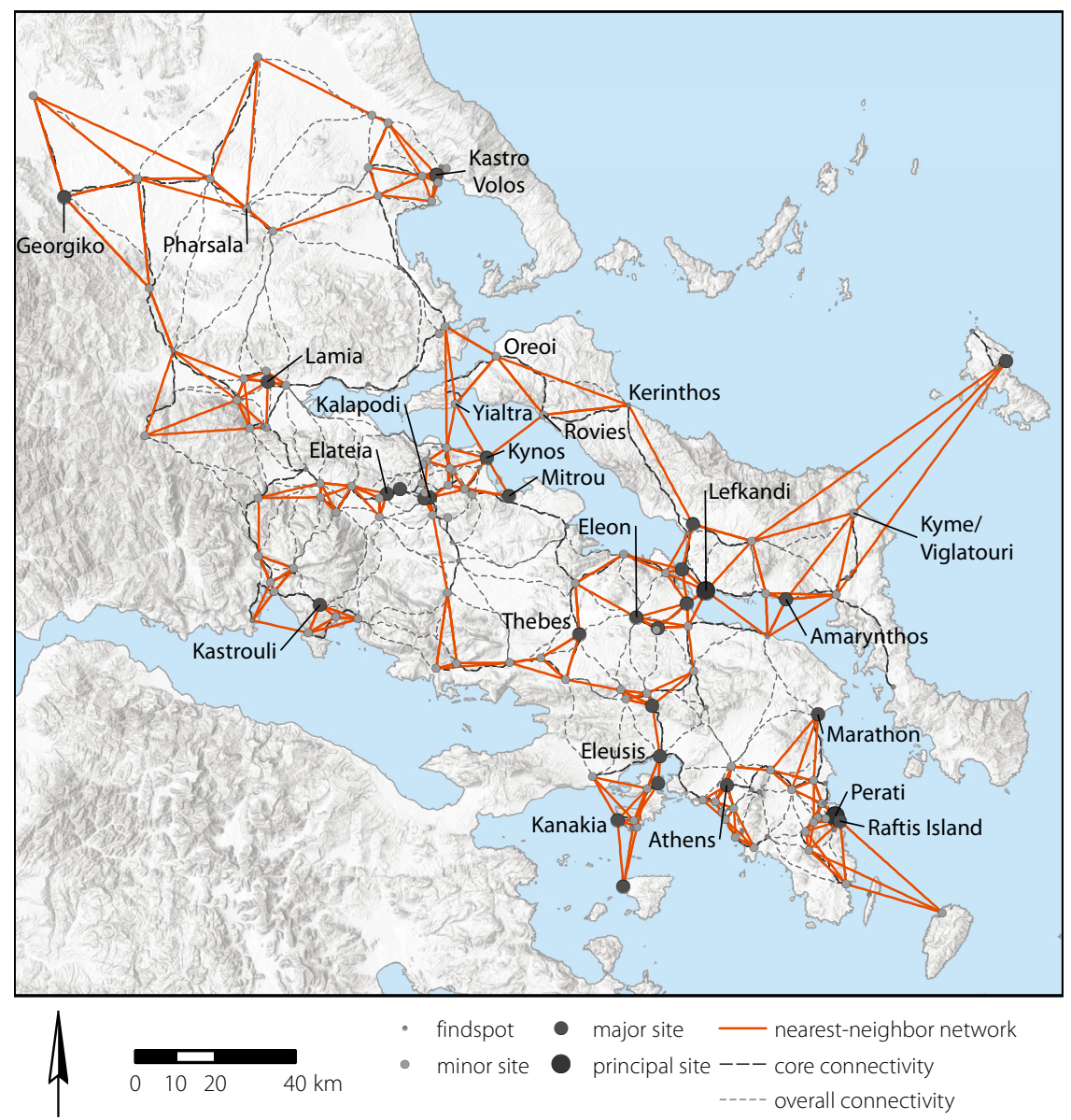

MAP 15. Postpalatial Bronze Age sites, joined by a connectivity model, with a nearest-neighbor network of communities (see also maps 14, 16, and appendix for additional place names).

There is a marked rise in the size and apparent importance of certain coastal sites on the Euboean Gulf. The sites that experienced the greatest growth are Kynos, Mitrou, and Lefkandi. While there are LH IIIB remains at all these sites, we see significant expansion in LH IIIC (Dakoronia 2003, 38; Sherratt 2006a: 304-5; van de Moortel 2009, 360-65). Kalapodi, while inland, is located on a major land routeconnecting the sea and the upper Kephisos valley/Great Isthmus Corridor-and also grows in significance in Postpalatial times (Felsch 1996, 2007; Niemeier 2016). Many of these sites have been subject to recent programs of fieldwork, which have dramatically altered our knowledge of central Greece in the Postpalatial Bronze Age (Lemos 2012; Knodell 2013; Kramer-Hajos 2016).

In keeping with this pattern, there are also sites on the Euboean Gulf that seem to have been important in the Palatial period but that wane in significance in the 
Postpalatial period. Larymna, for example, seems to have been established in $\mathrm{LH}$ IIIB as a maritime outlet for Orchomenos/Gla (see chapter 3, p. 81). It is fortified, and there is little to no agricultural land in the area, suggesting that it was built for a specific purpose-to serve as a port for a larger polity-and then more or less abandoned (Kramer-Hajos 2008, 129). Something similar may have happened at Glypha, which is located just across the Euripos from Chalkis. There are traces of LH IIIC settlement at Glypha, but the LH IIIA occupation was much more substantial, including buildings and walls, as well as numerous ceramic, glass, and metal artifacts; cyclopean walls have been documented there as well (SapounaSakellaraki 1987; Demakopoulou 1988). The apparent decline in activity at certain sites in LH IIIC may reflect a power shift away from places previously controlled by Thebes and Orchomenos in Boeotia. In Thessaly, the abandonment of Dimini and Pefkakia after LH IIIC Early, while Kastro Volos continued to prosper, may signal an association between the former that was overcome eventually by the latter. It is hard to say much about Athens itself, but a change in locational emphasis is also seen in eastern Attica. In particular, there is a pattern of sites clustering around Perati, with the settlement pattern thinning elsewhere, including around places like Marathon and Thorikos that had been of great significance during Palatial times (see maps 14 and 15).

In the connectivity model proposed here, very different patterns are apparent than in the Palatial period (compare maps 10 and 15). In Boeotia, interactions intensified around the central Euboean Gulf, especially near the Euripos. Another hub emerged around the bay of Atalanti, with Kynos and Mitrou on either side of it. Kalapodi appears as an important inland node on the confluence of land routes from Boeotia, Elis, Phthiotis, and Lokris. The Malian and Pagasetic Gulfs seem to have been less well connected at this time, especially with sites farther inland, and the nearest-neighbor connections drawn from these sites are often much longerdistance than others. In general, Thessaly appears to have been quite isolated: it is only in the vicinity of the Pagasetic Gulf that a significant density of sites was maintained. ${ }^{3}$ A natural interpretation of this pattern would be to suggest that it would lead to less frequent contacts between Thessaly and other regions, which seems to be borne out in the material culture of the period as well. While LH IIIC pottery styles are present at all of these sites, there is much greater regionalism visible than in the LH IIIB period, and, aside from these coastal locations, Thessaly diverges more than other regions from the LH IIIC regional style (often called a koine) that several authors identify around the Euboean Gulf (Desborough 1964, 146; Lemos 1998, 1999; Thomatos 2006; Van Damme 2017b, 411).

Euboea embarked on a new florescence of connectivity in LH IIIC, especially in the central part of the island, which would continue until the Archaic period. In

3. It is also interesting that in the Archaic and early Classical periods, Thessaly developed quite idiosyncratic political institutions, neither entirely aligned with the polis-states, nor with the tribal ethne (Morgan 2003; Decourt, Nielsen, and Helly 2004). 
the north Euboea was connected to the mainland via just a few nodes-the small settlements at Oreoi, Yialtra, and Rovies (see map 15). Kerinthos stands almost alone on the Aegean coast of Euboea, at some distance from any other sites. While Kerinthos was apparently isolated, its status as one of the few good harbors on the Aegean coast of Euboea, with another located at modern Kyme, would have made it a valuable stopping point for sea traffic.

Central Euboea underwent significant change in the Postpalatial period, and it is quite similar to East Lokris in this respect. There was no Mycenaean palace, although important sites certainly existed at several locations in Palatial times (see chapter 3). Most of these sites remained occupied in the Postpalatial period and some seem to have grown, though at Lefkandi the pattern was accelerated and it quickly became the preeminent site in the region (Sherratt 2006a, 304-5). In addition to sites located on the Euboean Gulf, the Oxylithos/Kyme area was clearly a participant in these networks. Like Kerinthos, this area was a seemingly isolated locale on the Aegean coast of Euboea, but it is also at one end of several major land routes that connect the Aegean to the Euboean Gulf. If the Kyme area were an important place for maritime connectivity in the Palatial period, as evidenced by the ingot finds discussed in the previous chapter, it likely remained so afterward, not least in terms of its connections to Skyros, which also maintained a significant occupation in LH IIIC. At Viglatouri, which the excavator identifies as Mycenaean and Geometric Kyme, remains of a substantial settlement have been found that demonstrate continuous occupation from the Early Bronze Age to the Geometric period (Sapouna-Sakellaraki 1998, 61). The broader organization of settlementmostly understood through little-known sites-seems largely to have been maintained in central and northern Euboea from Palatial to Postpalatial times, with a drop in the number of sites known from only a few finds.

Lefkandi itself seems to have risen quickly, perhaps on account of its location on the fertile Lelantine Plain, the nearby clay sources, and its shifting status within the political framework of central Euboea and eastern Boeotia. Its nonpalatial background and advantageous location near the Euripos allowed it to coopt longdistance trade networks while at the same time expanding local production to support a larger population. The site is also located on the principal land route that connects areas east of it to Chalkis. While a more northerly route is possible, it necessitates passing between Mounts Dirphys and Olympus, which would have been much more difficult (Fachard 2012, 103-5). By sea, Lefkandi had the advantage of a double bay, which could accommodate a great deal of maritime traffic. It was also an easy crossing to the mainland, making it an important go-between located just before the bottleneck of the Euripos. This position allowed Lefkandi to exert influence over the narrow strait without the risk of ships becoming trapped within Euripos itself.

On the other side of the Euboean Gulf, in Attica, a large division is apparent between eastern Boeotia and northeastern Attica, with the northernmost Attic site 
of any significance being Marathon. This absence results in the nearest-neighbor analysis effectively separating Attica from the rest of the study area (see map 15). While we should not interpret this to mean that Attica was a completely closed system, it may still reflect a relatively larger degree of isolation from the rest of central Greece. This is not to say that the region was isolated in the Postpalatial period. In fact, it seems to have prospered. Southeastern Attica has the highest density of sites of any area within the study region, and the cemetery at Perati reflects major connections with the outside world (Iakovidis 1980, 2003a, 2003b; Nightingale 2009). In a recent restudy of Perati, Murray (2018a) suggests that the exotica at Perati need not be interpreted simply as exotic status markers but should be understood rather as signifying specific aspects of mortuary ritual that reflect diverse origins. Drawing on evidence of foreign craftsmen remaining active at Tiryns in the Postpalatial period, Murray suggests that the evidence from Perati may reflect the establishment of a mixed community with members of various origins who dispersed from different parts of Greece in the wake of palatial collapse. This may also explain the lack of Palatial period evidence from the site, and it fits the wider pattern of movement toward the sea. ${ }^{4}$

The metal resources of the Lavriotiki were a continued draw for southeastern Attica, and indeed LH IIIC pottery has been found in a mineshaft in Thorikos (Mountjoy 1995b). It is possible that mineral resources became more widely available after the decline of a powerful center at Thorikos. ${ }^{5}$ The overall impression in Attica is a Postpalatial settlement pattern similar to that observed elsewhere, with settlements moving toward the coast. Moreover, we should note that, unlike many of the regions described above, southern Attica enjoyed close access to the Saronic Gulf, another locus of Postpalatial activity. Kanakia on Salamis maintained its significance well into the Postpalatial period, while another acropolis site at Ginani and several Submycenaean cemeteries throughout the island, including the Salamis Arsenal site, seem to indicate significant growth (Lolos 2001a).

Some isolation of Attica from the rest of central Greece is also reflected in the regionalism seen in its ceramic styles (Mountjoy 1999), which have more in common with Rhodes and the Cyclades than with elsewhere on the mainland. This reflects different external interactions, where Attica was involved in long-distance trade networks and stylistic trends separate from its neighboring regions. Indeed, connections between southeastern Attica, southern Euboea, and the Cyclades

4. A major LH IIIC settlement was recently documented on Raftis Island, just opposite the chamber tomb cemetery at Perati. The work is carried out by the Bays of East Attica Regional Survey (Murray et al., forthcoming; Bays of East Attica Regional Survey, accessed December 5, 2020, http:// bearsarchaeologicalproject.org/).

5. Ongoing work here, too, may prove enlightening, most notably with the Thorikos Archaeological Research Project of the Belgian School at Athens. See Thorikos Archaeological Research Project, accessed December 5, 2020, https://www.thorikos.be. 
represent a long-term trend, going back to the Neolithic and Early Bronze Age (Tankosić 2011; Cullen et al. 2013; Nazou 2017).

Thessaly is somewhat similar to Attica in witnessing a partial, but not drastic, shift in settlement pattern. Most noticeable is the thinning out of the area around Pharsala. After the Palatial period, it seems that communities in this area dispersed as part of a wider set of movements toward the sea. This thinning out may also suggest greater regionalism and divergence between the groups of communities that clustered around Volos and Lamia in the Postpalatial period, since Pharsala is found on the main land route in between. Near Volos things changed as well. Most sites around the bay of Volos and in the plain of Lake Karla (Boibeis) demonstrate continuity of occupation into LH IIIC. However, of the three "palatial" sites at Dimini, Pefkakia, and Kastro Volos, only the last was occupied after LH IIIC Early. This may indicate some sort of conflict and consolidation of power in the region during the LH IIIC period. Unfortunately, our state of knowledge is not such that we can say much more with any degree of certainty, though this may actually indicate a sort of centralization of regional power, not unlike what is seen at the same time at Lefkandi.

Malis does not appear to have had major changes in its settlement patterns during Postpalatial times. There is a small decline in site numbers, though the Spercheios valley and Lamia demonstrate strong continuity of occupation from LH IIIB to LH IIIC. This is not surprising, considering that, of any region of central Greece with a dense concentration of Mycenaean sites, this appears to be the one most distant from any known palace, both geographically and in network terms. There was, however, some diminishment in the overall scale of sites, most of which are cemeteries with continuity of use between LH IIIB and LH IIIC.

A similar pattern can be seen in Phokis, with continued but diminished occupation at several sites. Notably, the major fortified center at Krisa is not occupied in the LH IIIC period whereas the more coastal sites of Kirra and Itea Glas are-as, indeed, are several sites in the neighboring bay of Antikyra. This nexus of settlement in this part of the Corinthian Gulf contrasts with the negligible distribution of sites farther east in Boeotia, and it suggests that relations with Achaia (on the other side of the Corinthian Gulf) may have been maintained across the period of the palatial collapse. This settlement pattern also suggests that this access to the main land route north (the Great Isthmus Corridor) remained significant. Nevertheless, the central place at Krisa seems to have experienced the same pattern of abandonment seen at other major centers of the Palatial period, perhaps lending credence to its inclusion in some models of Mycenaean settlement as the possible location of a palatial site (Renfrew 1975, 15; Galaty and Parkinson 2007, 2). The lack of LH IIIC occupation at Krisa would therefore fit the wider regional pattern of rejecting sites with trappings of palatial society and shifting settlement orientations toward the sea (although the fact remains that there is no definitive evidence that Krisa was a palace). 
Given these shifts in the locations of settlements, as well as the reasons for growth and decline in particular areas, we can infer some significant lifestyle changes during the Postpalatial period. The first and most obvious is that populations were no longer living under the control, influence, or shadow of palatial regimes. Moreover, the end of the palaces was likely quite dramatic for people living at and around them, involving a certain amount of conflagration, death, and the abandonment of communities. In the absence of highly centralized authority, regional political organization was reconstituted more locally. This would have been felt most strongly in areas that had larger, more centralized palatial systems, most notably Boeotia, although even nonpalatial regions were in contact with and therefore influenced by their palatial neighbors. They responded to this disappearance, too. While this might be seen as a shift from authoritarianism to egalitarianism, the evidence suggests rather that new, different hierarchies emerged. The significant sites mentioned above still required organizational efforts for building projects, resource procurement, and, not least, maritime activities.

The connectivity model proposed here provides strong evidence for local and regional interaction in distinct patterns. Through the lens of peer-polity interaction we can see both characteristics of a shared symbolic culture and evidence for conflict in the form of relatively common destructions and upheavals at Postpalatial sites. Dakoronia $(2003,38)$ reports at least three destructions (two by earthquake and one by fire) at Kynos, and Lefkandi suffered similar misfortunes (Sherratt 2006a, 305-7). Earthquakes have been proposed in order to explain destructions at many other sites as well (Ambraseys 1996). This may make sense in a tectonically active area, yet sites along the Euboean Gulf especially must be regarded as highly connected, both by land and by sea, and earthquakes feature far too frequently as default explanations for destruction. ${ }^{6}$ Other, sometimes violent, explanations for destructions must also be considered. Murray $(2017,256)$ has characterized this period as more "chaotic" or unrestful than the previous. On the contrary, I would argue that the imposition of palatial systems was a significant act of societal disruption far greater than their collapse. Nevertheless, this may well have been a violent time in which new contenders for dominance and prestige in the region were in regular conflict with each other, and this conflict was most likely responsible for the majority of destructions seen during this period. I think that we should ultimately imagine a culture that combined subsistence agriculture and raiding - things that were present in Early Mycenaean and Palatial times, too, but were perhaps rebuffed or suppressed in certain areas by palatial institutions.

6. There is a long tradition of using earthquakes as an explanation for site destruction and culture change, especially in the Aegean, going back all the way to Arthur Evans and his insistence that Minoan Crete was not overrun by Mycenaeans from "the continent." More recent studies, of course, are more scientific and systematic (e.g., Stiros and Jones 1996; Jusseret and Sintubin 2017). There has been a focus especially on the Argolid in relation to the destruction of Mycenaean palaces: see essays in Stiros and Jones 1996. 
Interaction is manifest in other ways as well. Cooperation between communities must have existed alongside conflict and competition for resources. The drop in population and overall site numbers in the LH IIIC period would have in fact necessitated more connectivity between places than was seen in the previous Palatial period. Communities had to interact to remain viable-for the simple purposes of resource diversification between different microecologies, social storage, and intercommunity marriages. Modeled links are on the whole more coastal and involve greater distances (compare maps 10 and 15). In terms of how these connections happened, Dickinson $(2006,66)$ has highlighted the importance of movement on multiple scales, albeit in different terms, stating that "mobility might well be considered the most significant feature of the Postpalatial period, for it not only represents a continuing destabilizing factor, it underlines the limits on the coercive power of those trying to re-establish authority."

\section{Maritime Reorientations}

Ideological aspects of coastal settlement and increased amounts of maritime travel are apparent in other aspects of the material record as well. While palatial trade probably did not involve the ruling elite directly (that is, they do not seem to have gone on trading expeditions themselves), it was at least partly directed by them as exclusive consumers, and it likely involved agents of the palaces. With the settlement shift to the coast, however, and with aspects of maritime activity becoming less exclusively linked to palatial institutions, the sea must have loomed ever larger in the eyes of all people. In the sense of Tuan (1977), the sea represented an ever-present space of growing importance, through which people accessed places of special significance (other settlements, sanctuaries, and distant lands).

We also find evidence of anxiety and aggrandizement concerning the sea, as elite vessels (chiefly kraters used for drinking and serving at feasting events) bear depictions of ships with often violent imagery. Depictions of warriors and battle are not new in the LH IIIC period. Ship imagery appeared in the Mycenaean palaces of the mainland at Pylos and Orchomenos in the form of frescoes (Lang 1969; Brekoulaki et al. 2015; Spyropoulos 2015). There is, however, a new appearance of ship and siege imagery in LH IIIC on pottery (Petrakis 2011; Sauvage 2012), a portable medium designed for convivial contexts.

A dual maritime outlook - with the sea as a corridor and facilitator of movement but also as a dangerous place-may be reflected in figural representations found on painted pottery from Kynos and Lefkandi (Dakoronia 2006; Crouwel 2007, 2009; Lemos 2018). Sherds excavated from Kynos show a variety of maritime scenes (Dakoronia 1990, 1999, 2006). Figure 5a shows fragments of a krater with two boats, most likely engaged in combat; on a fragment from a lower part of the vessel a large fish attacks a fallen mariner, while other fish leap out at the people still on the boats. Figures $5 \mathrm{~b}$ and $5 \mathrm{c}$ show less fine fragments, though they are similarly 

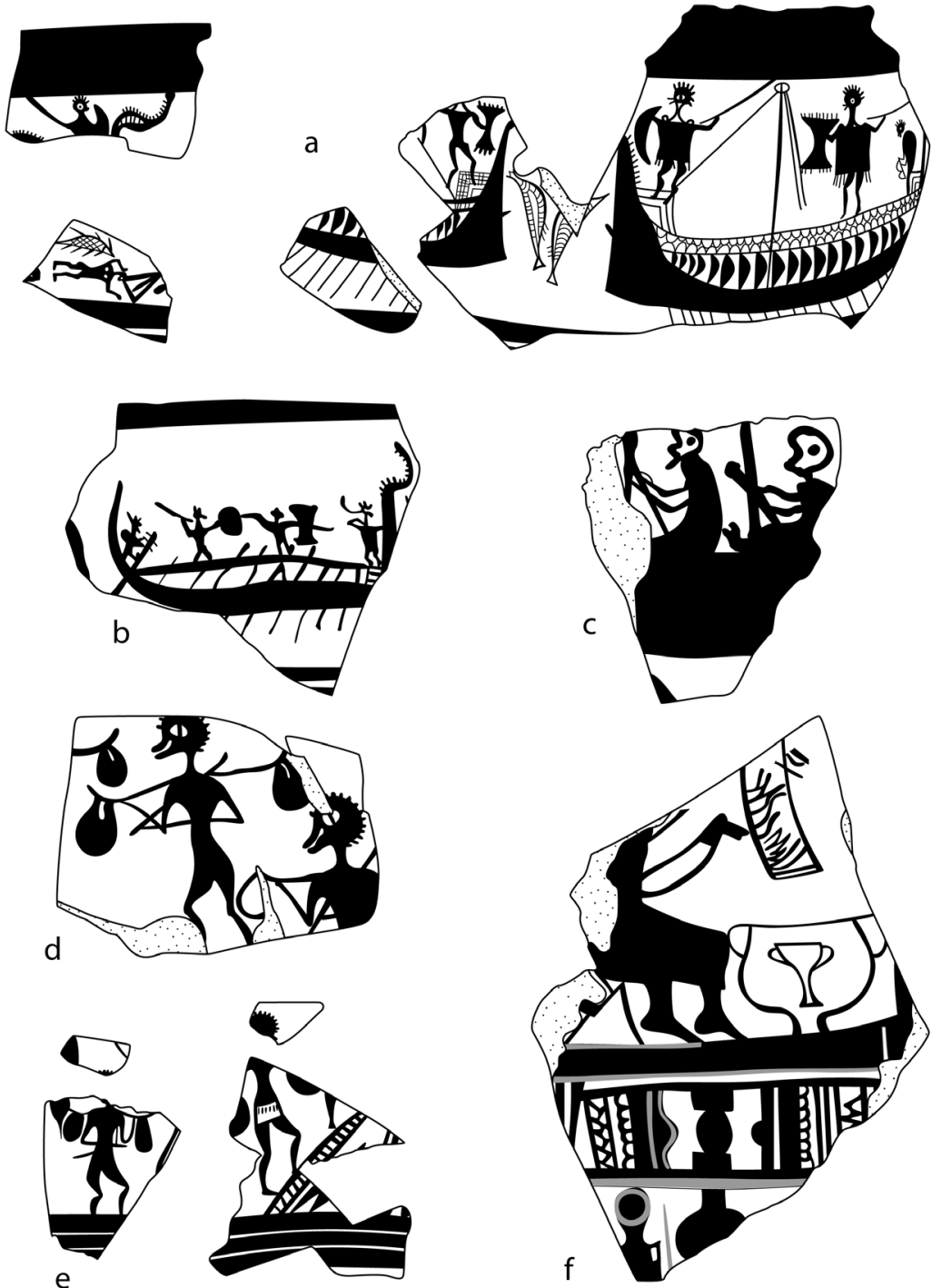

FIGURE 5. LH IIIC seafaring images from Kynos (a and b) and Lefkandi (c); sherds from "siege kraters" from Thebes (d) and Kalapodi (e); a sherd from "feasting krater" at Lefkandi (f) (illustration by Christina Kolb, after Dakoronia 2006; Evely 2006, pl. 71; Niemeier 2013, 36, fig. 2; Petrakos 2014; Lemos 2018).

styled and display equally combative scenes. These images seem to reflect a culture for which maritime activity and conflict were in common thought, at least for the craftspeople producing these depictions-as well as for their consumers-which is a major departure from the previous Palatial period. Moreover, the sea is cast 
as a dangerous place, owing both to other people and to the nonhuman world. In addition to maritime imagery, "siege kraters" from Thebes and Kalapodi may preserve the memory of certain raids or other conflicts, or perhaps represent a generic theme of interest (figure $5 \mathrm{~d}$ and $5 \mathrm{e}$ ). Whether these are meant to represent real or imagined battles is impossible to know, but vessels bearing such images would have played an important role in social life, reflecting practices of communal drinking in which images served to express access to special products as well as to a particular type of imagery that was associated with status-building activities of seafaring and battle. Figural painting was still rare, and its distribution was quite uneven (Rutter 2014a). The owner of such a vessel would thus draw attention to such status activities while at the same time acting as host-another expression of social power. This is quite different from what we see in the Palatial period, when vase painting more often depicted symbols of elite power (individuals in chariots or powerful animals) than group activities like sailing or fighting.

While such imagery is not widespread, it is significant that it appears at some of the largest and best-connected sites on the Euboean Gulf, Kynos and Lefkandi, both of which seem to have suffered a series of destructions throughout the Postpalatial Bronze Age. While such a rivalry is not preserved in any particular mythohistorical accounts of the area, we might imagine competition between powerful rivals over control of this important maritime corridor (not unlike the territorial rivalry described in Boeotia, between Orchomenos and Thebes).

\section{Political Authority and the Constitution of Society}

Postpalatial societies formed new orders after the rejection of palatial systems. While occupation continued at some palatial sites, the physical and institutional structures of the previous polities-that is, the palaces themselves-were quite forcibly destroyed. Such patterns have been identified also in other complex polities that underwent dramatic social change or collapse, providing instructive examples of this type of rejection of institutions. Smith $(2003,168)$ describes a similar process in the Caucasus, whereby agents of the kingdom of Urartu destroyed structures associated with previous Late Bronze Age and Early Iron Age polities as an act of memory erasure and to displace the subjects of earlier regimes. Another relevant comparison might be the destruction of churches in France after the French Revolution (Clay 2003). Such acts of iconoclasm associated with political upheaval or overthrow occurred in many ancient polities-for example, in Mesopotamia and Mesoamerica-where symbolic destructions of material objects were deployed as enduring acts of violence against the collective memory of a place. Whatever the agency of the original destruction of the Mycenaean palaces (foreign invaders, interpolity conflict, popular uprising), the rejection of institutions that followed was lasting and reflects new interests in defining polity in opposition to them. In this way, the palatial destructions were an act of political production for some groups rather than simply the failure of others. 
Large-scale resettlement is another mode of claiming authority in a landscape (Smith 2003, 168-69). In early Greece, such a deliberate strategy may be reflected in the depopulation of palatial territories and potential relocation to other areasin central Greece or elsewhere. At the same time, there were also acts of reoccupation and rebuilding at previous locations of palatial authority, though in a different style. For example, the lower citadel of Tiryns was rebuilt extensively in the Postpalatial period on a different plan, while a new, smaller megaron was built over about half of the Palatial megaron (Maran 2001). Whatever the specific agency, we can see that new forms of political authority rose as societies were reconstitutedmost likely in response to the rejected modes of palatial organization.

The degree of reorganization or change varied substantially by region, with the most dramatic shifts limited to previously palatial areas, as seen in the settlement data described above. Previously nonpalatial areas were affected too. Social integration took place both through the routines of everyday life, and in the dialectic construction of political authority (in the broad sense of Bourdieu 1977; Giddens 1984). Practices in the construction and legitimation of authority were smaller in scale than what was found in the palaces, and they were oriented more locally than regionally. Altogether, the constitution of political authority within the broader fabrics of society seems to have been an iterative, largely local process. Nevertheless, certain practices were shared throughout central Greece, even if there were apparent differences in scale. Certain of these, especially feasting, have direct antecedents in the Palatial period (and even earlier), though the practices were reconfigured as more local, less institutionalized negotiations of sociopolitical power.

Postpalatial society in general seems to have followed patterns established in the Early Mycenaean period. These were also maintained throughout the Palatial period in nonpalatial areas. As in the Palatial period, we should imagine a range of nonstate modes of social organization (see chapter 3 ). Nonpalatial societies in the Aegean might find parallels in middle-range ranked societies-which can also be characterized as transegalitarian-where social roles, status, and power relationships are somewhat informal and fluid (Ames 2008). The Postpalatial societies of central Greece are probably best characterized as occupying various positions along such a scale, represented by complex communities that exhibit a variety of modes of social organization. While centralized hierarchies no longer existed on a regional scale, local hierarchies became more apparent in certain areas, with more similarly sized centers, possibly controlled by nonhereditary leaders in regular contact and competition with one another (Whitley 1991, 184-86; Dickinson 2006, 110-11).

While it is difficult to know whether leadership was acquired or inherited, some combination of these characteristics seems most likely. Evidence for the continuous use of elite family chamber tombs in certain areas-Elateia, Medeon, and the Spercheios valley - suggests a maintenance of social status over generations, a trait that 
is also apparent in the chronologically amalgamated world of Homer. We might, then, imagine loose, sometimes hereditary systems that were not supported by formal institutions (such as a palace) and that also depended on the acquisition and maintenance of status on an individual basis. Systems of rank, status, and inequality were certainly present, but they were diverse and subject to rapid change on local or even individual levels.

Feasting played an important role in sociopolitical organization during this period (see, e.g., Dietler and Hayden 2001; Hitchcock, Laffineur, and Crowley 2008; Small 2019). Wright (2004a) notes that feasting can be traced from the Early Mycenaean period through the Postpalatial Bronze Age and Sherratt (2004) has linked aspects of ritual feasting seen in Homer to Mycenaean antecedents that were preserved through the Postpalatial period and into the Early Iron Age; these were associated especially with rulers' dwellings (Mazarakis Ainian 1997; Fox 2012; Alexandridou 2018; van den Eijnde 2018). In this way ritual feasting was a means of constituting and reinforcing asymmetrical power relationships within a society, as the host demonstrated the capacity to provide, entertain, and bring communities together. In the archaeological record of central Greece this is manifest in the forms of kraters, cups, and bowls as the most finely made and heavily decorated aspects of ceramic assemblages, suggesting that the practices with which they were associated (communal drinking and feasting activities) remained at the forefront of integrative social acts. In the Palatial period (in palatial areas), palaces coopted and institutionalized such practices, as evidenced in Linear B accounting concerning such events. In Postpalatial times, such practices were attached rather to individual agents who relied on the practice in the construction of personal (rather than institutional) authority. As in other cases, the palaces represent a scalar difference in a type of activity that elsewhere demonstrates a substantial continuity of practice. Van den Eijnde $(2018,10)$ looks to feasting as a "critical tool in building group identities, especially in the context of early states." Feasting is also a rather more general phenomenon, powerful outside of state contexts particularly for the implicit, noninstitutionalized power relationships it projects. The early Greek case is perhaps a cyclical one, where such social practices waver between the informal (Early Mycenaean, Postpalatial, Early Iron Age) and the institutional (Palatial, early polis) in political life. Nevertheless, more informal, perhaps "personal" contributions to feasting events likely persisted through palatial times as well, as Nakassis (2012) has argued in the case of Pylos based on Linear B texts that seem to record the generosity of the wanax (they use his personal name, e-ke-ra2-wo, in some places and call him the wanax in others). And as Small (2019) argues, feasting itself can serve also to create new social roles and institutions.

An even more significant change can be observed in the Postpalatial period, when feasting practices took on an interregional character in certain areas, chiefly in zones that did not witness centralized integration in palatial times, previewing 
certain characteristics of later interregional sanctuaries (de Polignac 1995). Ritual drinking and dining practices are evident at Kalapodi as modes of integrative and competitive social interaction, involving elites from the surrounding regions (Livieratou 2011, 150). Kramer-Hajos (2008, 141-43), drawing on faunal analyses by Stanzel (1991), argues that these practices were linked to the worship of Artemis, based on the presence of large numbers of deer bones, tortoise shells, and high-quality pottery of the aforementioned types. It is significant that Kalapodi is identified as the oracle of Apollo at Abai (Niemeier 2009) and it is probable that both deities were worshiped at the site-a frequent coincidence known also from later times.

Developments at Kalapodi may be part of a wider reorientation, in which regional, large-scale feasting events shifted toward ritual sites along important routes, both coastal and inland. In the LH IIIC period, for example, we see Amarynthos thrive, and in the area of the later sanctuary there is also Postpalatial and Early Iron Age material (Fachard et al. 2017; Reber et al. 2019). From later times, there are Artemis and Apollo sanctuaries at several other locations along the Euboean Gulf, including Plakari, Brauron, Eretria, Aulis, and Histiaia (see also Kowalzig 2018). While we do not have solid evidence of LH IIIC cult activity at these places, the existence of later sanctuaries at these locations may indicate a diachronic pattern of this type of practice starting at Kalapodi (and possibly at Amarynthos) in the Postpalatial period, and then spreading through central Greece in the Early Iron Age.

This trend continues at Kalapodi throughout the Early Iron Age and should be seen as a precursor to the regional sanctuaries in the eighth century and the early Archaic period.7 McInerney (2011, 99-101) has recently shown that Kalapodi was the main regional sanctuary in central Greece until it was eclipsed by Delphi in the early Archaic period. In Postpalatial times, Kalapodi provided a venue for regional meetings between local elites and a place to engage in competitive aggrandizement, consumption, and display. It was in the Postpalatial Bronze Age, then, rather than in the Geometric period, that regional sanctuaries first became significant as decentralized loci of religious practice and began to play an important role in mediating the political landscape. Sealstones from Kalapodi indicate that ritual activity goes back to LH IIIA (Niemeier 2016), which suggests that such practices may have begun in nonpalatial or liminal areas even in the Palatial Bronze Age. This may have begun as a nonpalatial response to the political and administrative centralization of religious practice at the palaces, and then later came to thrive in Postpalatial times.

On a local level, smaller-scale feasting practices can be observed at Kynos, Lefkandi, and Mitrou. At Mitrou, such behaviors have definite antecedents in the 
LH IIIA2 period (Vitale 2008). At Lefkandi and Kynos, drinking vessels stand out with respect to quality and decoration (as in other places and times), which suggests that these are aspects of material culture deployed by a subset of society with special access to the "finer" things for a specific purpose-sharable marks of distinction in group eating and drinking events. For example, a pictorial krater from Lefkandi depicts feasting equipment (table, kylix, krater) and a seated figure (figure 5 f). People came together to eat, drink, and socialize, and important individuals or groups acted as hosts. In this way, social bonds were reinforced and leadership was performed through everyday practices. Most importantly, such events served the purpose of bringing together people on a local scale in particular places, establishing new localizations of political authority, both at settlements and the interpolity contexts of regional sanctuaries. Such political acts were no doubt carried out on smaller scales throughout the landscape, too, as evidenced by the frequent occurrence of drinking sets in Postpalatial households and funerary contexts (Van Damme 2017b, 403-5; Small 2019, 102).

A further proxy for the emergence of leadership in new places can be found in evidence for storage. LH IIIC impressed pithoi from Kalapodi, Mitrou, Kynos, and Lefkandi suggest that storage practices were meant at least partly for display and that they carried sociopolitical messages as well (Lis and Rückl 2011). While there is again a scalar difference between the evidence at these sites and at previous palatial sites, there was nevertheless a focusing of resources in particular places, associated with the storage of staple products as wealth and perhaps its occasional redistribution in the form of communal events. LH IIIC assemblages of large cooking pots from Tiryns and Lefkandi also indicate that some houses had a much greater capacity to prepare and serve food than others (Lis 2015, 108). While there is no evidence for centralized or communal storage during the Postpalatial period, the storage capacities of Postpalatial households from several parts of Greece indicate that dry goods were being stored at a level above subsistence; there is also evidence for commensal dining in courtyards or large halls in households (Van Damme 2017b, 379-80). Together, this evidence suggests an individual- or household-oriented model for social display and the accumulation of prestige.

Rural populations comprised the wider world beyond the relatively few major sites serving as central places. In previously palatial areas these populations would have had to reorganize following the collapse of the palaces that seem to have, at least partly, centralized aspects of regional agricultural consumption. Risk-buffered farming has the opposite, decentralizing goal, necessitating greater connectivity on a regional scale between individuals and groups. This type of basic household- and community-based agriculture would have been the norm in nonpalatial systems. The highly varied landscapes of central Greece were much better suited to this subsistence strategy than large-scale agriculture on sprawling plains. Halstead (2006, 26-31) discusses the dependence in Neolithic Greece of neighbors on one another in times of harvest for labor, and at all times for protection, 
exchange, and marriages. This shows up in later periods too, since risk-buffering strategies were often developed to adapt to new structural conditions in societyfor example, in the Hellenistic period (Gallant 1989, 393). This mode of agricultural production contrasts sharply with the centralization of territorial resources seen in Palatial times. In the Postpalatial period, long-term strategies for risk buffering would have involved intercommunity connectivity, while short-term solutions to problems would have likely involved raiding for existing products rather than the acquisition of potentially productive territory. This is a fundamentally different relationship to land than can be seen in palatial systems, and also one that would have been antagonistic to them, which we can see especially if we extend such behaviors to nonpalatial areas during the Palatial period. This may offer yet another explanation for the palatial obsession with defensive architecture.

Conflicts between individuals and groups are characteristic of all societies, particularly in times of transition. As the political landscape of early Greece shifted, new opportunities and pathways to power opened on both local and regional scales. That conflict, especially maritime conflict, had become a significant feature of life in the Postpalatial period is evident in site destructions and in the figural representations discussed above (see figure 5), as well as in the increasing numbers of warrior depictions from a variety of LH IIIC sites (Crouwel 2007, 2009). This may represent a renewal of what Kramer-Hajos (2016) calls the "warrior ethos" of the Early Mycenaean period. Intercommunity conflicts can also be inferred from the choice of defensible site locations. While these are not the difficult-toaccess refuge settlements of Crete or elsewhere in the Aegean (Nowicki 2000; Wallace 2010, 95-100; see also Haggis 2001), nearly all the major sites highlighted here (Mitrou, Kynos, Kastro Volos, Lefkandi, Amarynthos, Viglatouri, Athens) are either located on hilltops or are defensible promontories, which suggests that defensibility, along with access to the sea, remained a key concern.

The social changes at the end of the Palatial period, as well as the attendant shifts in settlement patterns, required new strategies of making connections between individuals and communities. Beyond these bare requirements for survival and sustainability, social practices would have developed to bring people together and certain individuals would have emerged "on top" in reformulated systems of social ranking, whether as a result of charisma, greater access to resources, or martial prowess. At any rate, the importance of certain integrative practices was not lost, and new local leaders emerged in all likelihood immediately after the palatial collapse if they were not already in place. Jung (2016) has argued that local leaders operating parallel to palatial systems may have played a role in the palatial collapse. This antagonism is a likely proposition that also helps to explain the lack of revival of palatial practices. Thus, hierarchy-as constituted and maintained through social integration and exclusion-was not new in this period; rather, it was reoriented. What is perhaps most novel is the emergence of regional ritual centers like Kalapodi (and possibly Amarynthos) as points of convergence and 
mediation for people from different communities, which anticipates later developments in Greek politics and religion.

\section{CRAFTING IN NEW COMMUNITIES, RECONFIGURING PRODUCTION}

Much of the settlement evidence discussed above comes in the form of pottery belonging to the LH IIIC style, which is related to-but distinct from-its Palatial precedents. While the LH IIIA and LH IIIB ceramics of the Palatial period demonstrate a higher degree of uniformity across regions, there is also a fair amount of regionalism present, especially in Euboea. LH IIIC ceramics show much greater regional variability (Sherratt 1980; Mountjoy 1999). The higher degree of uniformity in Palatial Mycenaean fine wares was the result of two related factors. First, this uniformity represented the emergence of regional production centers, some of which were located at palaces themselves-for example, at Thebes (DakouriHild 2005, 185). The degree to which these were under the control of the palace is not well understood, and ceramic production is not widely represented in the Linear B tablets (Galaty 2007, 86). That being said, production and distribution on interregional and, especially, macroregional scales suggests some form of centralization, although this may well have more to do with consumption than production or with the fact that certain regions, such as the Argolid, exported large quantities. Moreover, it is clear that certain ceramics were being produced to suit elite tastes that were shared across the Mycenaean world. This can be seen as the result of regional integration and interregional interactions between polities, both palatial and nonpalatial. In some ways, the pattern of uniformity seen in the Palatial period represents integrated views of production and consumption, which had grown through the Middle Helladic and Early Mycenaean period. From this standpoint the LH IIIC stylistic divergence might be seen as a stylistic regression.

As an explanation for the above shifts, I suggest that the collapse of the palaces led to a dispersal of craft producers, who were formerly associated with palatial polities and who worked and trained apprentices in new social contexts in which ceramic production happened on local to regional scales. That is to say, pottery produced at local scales was then distributed through regional consumption networks, some of which were farther reaching than others. This explains regional divergences in style, on the one hand, and the surprisingly wide dispersal of sites exhibiting local styles of Mycenaean pottery during Postpalatial times, on the other.

Local patterns of LH IIIC ceramic styles fit the settlement pattern groupings created by the nearest-neighbor analysis fairly well, lending strength to the hypothetical connections generated in the network model (see map 15). Production itself seems to have occurred at the larger sites in the region, which suggests a degree of local-level centralization. Kilns have been excavated at Kynos and Pherai, and the clay sources at Phylla, near Lefkandi, seem to have been exploited for 
millennia on either side of the Postpalatial period (Dakoronia 1993, 125; BatziouEfstathiou 1994; Kerschner and Lemos 2014). Lefkandi itself, then, was a likely production center as well.

LH IIIC pottery is also found dispersed somewhat more widely around the eastern Mediterranean. Population movement has long been used to explain this expanded distribution (Desborough 1972, 20-21; Dickinson 2006, 62-67; Murray 2017, 199-200). An additional (and likely) possibility is that craftspeople especially were on the move, along with goods and ideas, a phenomenon well documented for a variety of times and places in the Mediterranean (Blake 2008; Lis, Rückl, and Choleva 2015; Aslaksen 2016; Kiriatzi and Knappett 2016). By contrast, Yasur-Landau (2010), based on the magnitude of changes seen in material culture production in Cyprus and the Levant, has argued for the movement of whole populations. Whether we are talking about migration or travel, mobility is certainly present, and on a larger scale, affecting more members of society than in Palatial times. The most likely scenario is that mobility was expanding in the form of both travel and migration.

\section{Pottery Networks in the Euboean Gulf}

Stylistic groupings of pottery assemblages are often rendered through network models (Knappett 2013; Blake 2014). Sherratt (2006b, 218-20) notes a great deal of similarity between LH IIIC ceramics from Lefkandi and several other sites in central Greece, which can be illustrated as a simple stylistic network (map 16). We should note that no sites in Attica are included in this grouping, an exclusion also in the nearest-neighbor network of communities (see map 15). While these similarities should not be taken to mean that Lefkandi was the only production center for the whole region, they do indicate enough identical or shared elements of style to suggest frequent and consistent links through which other ideas could have flowed. These similarities are apparent in both stylistic features and (necessarily) sequences of production. Indeed, the presence of kilns at Kynos and VelestinoPherai indicate local production, though clearly with a stylistic repertoire shared throughout a much larger region (Sherratt 2006b, 220).

The chronology of the extent of these similarities also has some explanatory power. What is significant here is the quantity of stylistic links for each period, as well as the question of when-in what period-new links are formed. The similarities of style during Phase 1 of the LH IIIC period at Lefkandi are telling, and they would seem to indicate a holdover from earlier modes of production. The similarities would have evolved out of the commonalities of the previous period and then spread via the dispersal of craftspeople to growing communities following the collapse of the palaces. This is indicative of already widespread styles coalescing in certain areas rather than a particularly Lefkandiot style dispersing. The chronology is especially important for Orchomenos and Eutresis, which only have LH IIIC Early pottery (Lefkandi Phase 1), indicating holdout at these places 


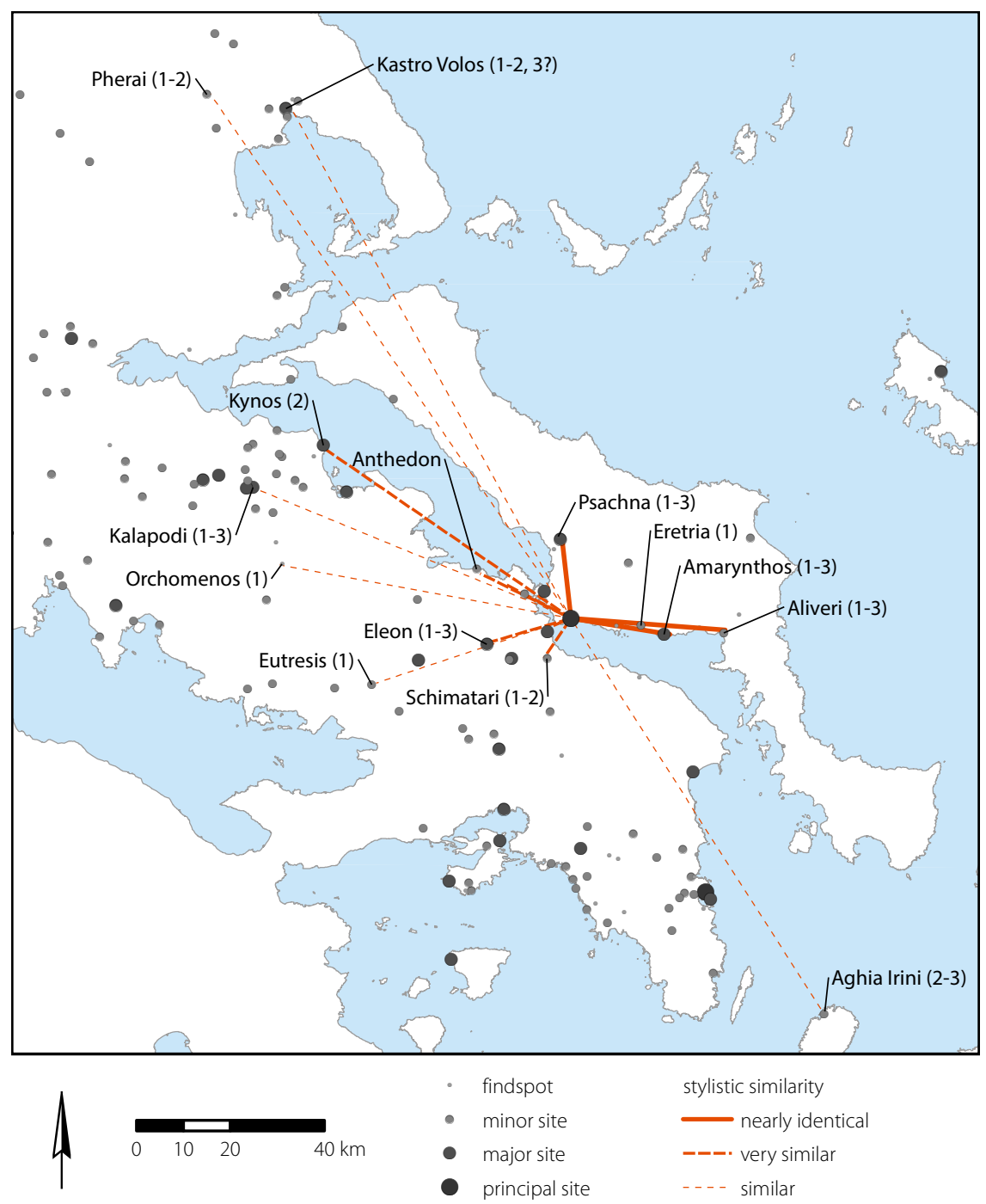

MAP 16. Lefkandi pottery network and settlement pattern in the Postpalatial Bronze Age, showing degree of similarity of pottery between Lefkandi and other major sites (connecting lines) and Lefkandi LH IIIC phases represented at the site (1-3, in parentheses) (data from pottery study by Sherratt 2006b, 218-19).

that had been significant during the Palatial period before they were eclipsed by new centers reaching their apogee in LH IIIC Middle. The distribution of Phase 2 ceramics is more reflective of the prosperity that sites on the Euboean Gulf enjoyed in this period generally, and it also shows the beginning and flourishing of stylistic links with more distant places like Kynos and Kea. Phase 3 is much 
less widespread, which could well indicate difficulties that sites such as Lefkandi and Kynos experienced in this final stage of LH IIIC: Sherratt (2006a, 307) notes that the architecture of Lefkandi in its final phase was heavily degraded although occupation was maintained; a similar pattern is found at Kynos (Dakoronia 2009).

It is in LH IIIC Middle (Lefkandi Phase 2) that a shared pattern of ceramic production and consumption is apparent across the northern and central Euboean Gulf, which fits well with the nautical figural representations of the period (figure $5 \mathrm{a}-\mathrm{c}$ ) and the overall connectivity and architectural elaboration demonstrated at the major sites. The crucial innovation in this phase was the florescence of figural scenes, which quickly spread to several locations, demonstrating ideological and technological links (Thomatos 2006, 141-42; 2007). The northern and central Euboean Gulf also experienced the most violent destructions during this period, which are seen most clearly at Kynos and Lefkandi. These destructions, however, cannot be compared to the systemic collapse of the palaces at the end of LH IIIB, since destructions are in almost all cases followed by quick recovery and continuity into the Protogeometric period. Indeed, it may have been the local and yet competing nature of craft production in the Postpalatial period that led to the innovations we see in the Protogeometric style.

Attica is not part of this stylistic network throughout LH IIIC. Its attention seems to be turned toward the Cyclades (especially Naxos), the Dodecanese, and the west coast of Asia Minor (not least Miletos) rather than the Euboean Gulf. Desborough $(1964,146)$ called this an Aegean koine, though there are doubts about the appropriateness of this term (Deger-Jalkotzy 1998, 115; Vlachopoulos 2003, 231; Thomatos 2006, 145-48). Whatever we call it, there are shared characteristics that were likely brought on by higher degrees of connectivity between certain places. In Attica, these connections are most apparent at Perati, which has the largest corpus of excavated LH IIIC material by far, though other important assemblages come from Athens, Aghios Kosmas, and Thorikos (Mountjoy 1999, 496-99). Other long-distance relations represented at Perati were to the east, although by LH IIIC Late Attic pottery begins to have more in common with that of the Euboean Gulf (Mountjoy 1999, 53). Much of this is so-called White Ware, which now appears to have been locally produced but also shows links between Attica, Euboea, and the islands to the east (Lis et al. 2020b). This may indeed have been crucial in establishing a network through which the Attic Protogeometric style spread so rapidly in the subsequent period. At the same time, the divergence of Attica from the rest of LH IIIC central Greece may help explain the rather isolated (and problematic) phenomenon of Submycenaean pottery. ${ }^{8}$ Finally, it seems to be the case that potters themselves were on the move, at least in certain cases. A recent study of cooking pots from several locations along the Euboean and Pagasetic Gulfs indicate that a particularly Aeginetan chaine opératoire was in use, and that this type of

8. On the problematic nature of the term Submycenaean as an independent phase, rather than a regionally specific style, see Rutter 1978; Papadopoulos et al. 2011. 
technology transfer would have happened in the context of both itinerant activity and permanent relocation (Lis et al. 2020a). This is also quite likely to have been the case at other times and with other industries.

\section{Metal Production and Consumption}

In addition to pictorial pottery in LH IIIC Middle, metal artifacts, too, seem to indicate the proliferation of a warrior ethos, most clearly in so-called "warrior tombs" or "warrior burials" (Cavanagh and Mee 1998, 89-97; T. J. Papadopoulos 1999; Deger-Jalkotzy 2006; Steinmann 2012). Foremost among the various prestige goods that distinguished these graves were metal artifacts, including weapons, vessels, and toiletries such as combs, razors, tweezers, and mirrors (Deger-Jalkotzy 2006, 152). These types of graves are found widely in Achaia, although they are relatively rare outside of the northwest Peloponnese and Epiros (Deger-Jalkotzy 2006, 154; Douzougli and Papadopoulos 2011). The Argolid and Boeotia, in particular, stand out because they lack such burials. In the case of Boeotia, DegerJalkotzy (2006, 167-68) suggests that this is owing to the history of research and lack of discovery rather than to a lack of presence. Kramer-Hajos $(2016,164)$ points to the cemetery at Perati and two swords found in Euboea at Avlonari and Palioura-both from nonfunerary contexts-as evidence for "warrior tombs" in central Greece. On their own, these are not particularly strong arguments, but other categories of evidence (site destructions and iconography) suggest that the ideologies that produced warrior burials in Achaia may also be found in central Greece, again in areas that were not previously within the remit of palaces. Metal consumption would have been a key element of this ethos.

Linear B records from the Palatial period in Pylos provide us with a good example of the scale and location of metalworking in relation to the palatial economy. The Jn series of tablets mentions around 270 smiths, varying allotments of metal, and divisions of labor (Ventris and Chadwick [1956] 1973, 25259; J. Smith 1993; Michailidou 2008, 534-35; Nakassis 2013a, 74-102). Whitelaw $(2001,9)$ places metal production somewhere between the palatial and nonpalatial sector, although Blackwell (2018) has recently associated metal hoards at several mainland sites from the Palatial period with allotments from and controlled by the palace. Like pottery production, metal production industries were specialized occupations before the time of the palaces, and they certainly were practiced outside palatial areas as well. Following the collapse of palatial systems, metalworkers from palatial areas-the most active in the Mycenaean world-would have needed to find new locations and reconfigure production in the absence of administrative structures. Self-organization, rather than central organization, had major consequences for connectivity. In the Postpalatial period, production remains from settlements are extremely scant, although coastal examples from Mitrou, Lefkandi, and Aigeira may indicate that maritime locations were also significant for this type of industry (Evely 2006, 288; Alram-Stern 2007, 17; Blackwell and O’Neill 2014). 
Possible explanations for the lack of production remains at major sites include traveling smiths or smiths connecting to long-distance and regional networks of resource procurement and product distribution that did not leave substantial material traces; in fact, this lack of production probably stems from a mixture of both things. The crucial element here-one that is not present in the Palatial period and does not apply to ceramic production-is that smiths must have been much more active in their connection to long-distance networks. In the first place, metal sources are usually located at some distance from known production sites and, in the second, the centralized import of raw materials was not happening at palatial sites. Recycling must also be taken into consideration, and the presence of scrap found in bronze hoards suggests that this was an important activity at various times and places in the Bronze Age (Budd et al. 1995; Knapp 2000; Blackwell 2018; Sherratt 2000, 87-88). The Cape Gelidonya wreck (see map 17), which dates to the beginning of the Postpalatial period (ca. 1200 BCE or slightly later) and had LH IIIC pottery on board, provides evidence for traveling smiths and recycling in the form of metal scrap and bronze-working tools found in the cargo, along with more conventional ingots (Bass 1967). This evidence is in contrast to the earlier (Palatial period) Uluburun wreck, whose cargo of bulk goods (copper and tin ingots) and prestige items fits much better with the palatial model of consumption described above.

In central Greece, Lefkandi has the most significant metal production remains dating to the Postpalatial period. This is unsurprising, given its key location, demonstrable relations with Cyprus, and history of excavation. Finished products, production slag, crucibles, and molds were all found at the site (Evely 2006, 288). Recent excavations at Eleon have uncovered evidence for lead working, and there are also partial molds from Athens, including from the Mycenaean fountain (Van Damme, personal communication). Anthedon also has remains of bronze working (Rolfe 1890, 104-7; Catling 1964, 296-97; Schläger, Blackman, and Schäfer 1968). Finished products are fairly widely dispersed, but they are often difficult to date to LH IIIC specifically, since all but one of the Aegean sword types that appear in LH IIIC also appear in other periods (Molloy 2010, 405). Moreover, these are often decontextualized and are reported to come from tombs in generalized locations. Perati, unsurprisingly, provides the widest array of excavated metal artifacts from this period, which fits models either of conspicuous deposition of wealth in funerary contexts (Iakovidis 1980) or a community of displaced craft specialists (Murray 2018a). Either way, metal production and consumption remained an important social practice carried out within and across multiple regions.

\section{AN AGE OF MOBILITY}

The Mediterranean world witnessed dramatic shifts between ca. 1200 and 1050 BCE, especially in terms of expanding maritime activity (Broodbank 2013, 460-72). While political upheaval took place throughout much of the eastern 

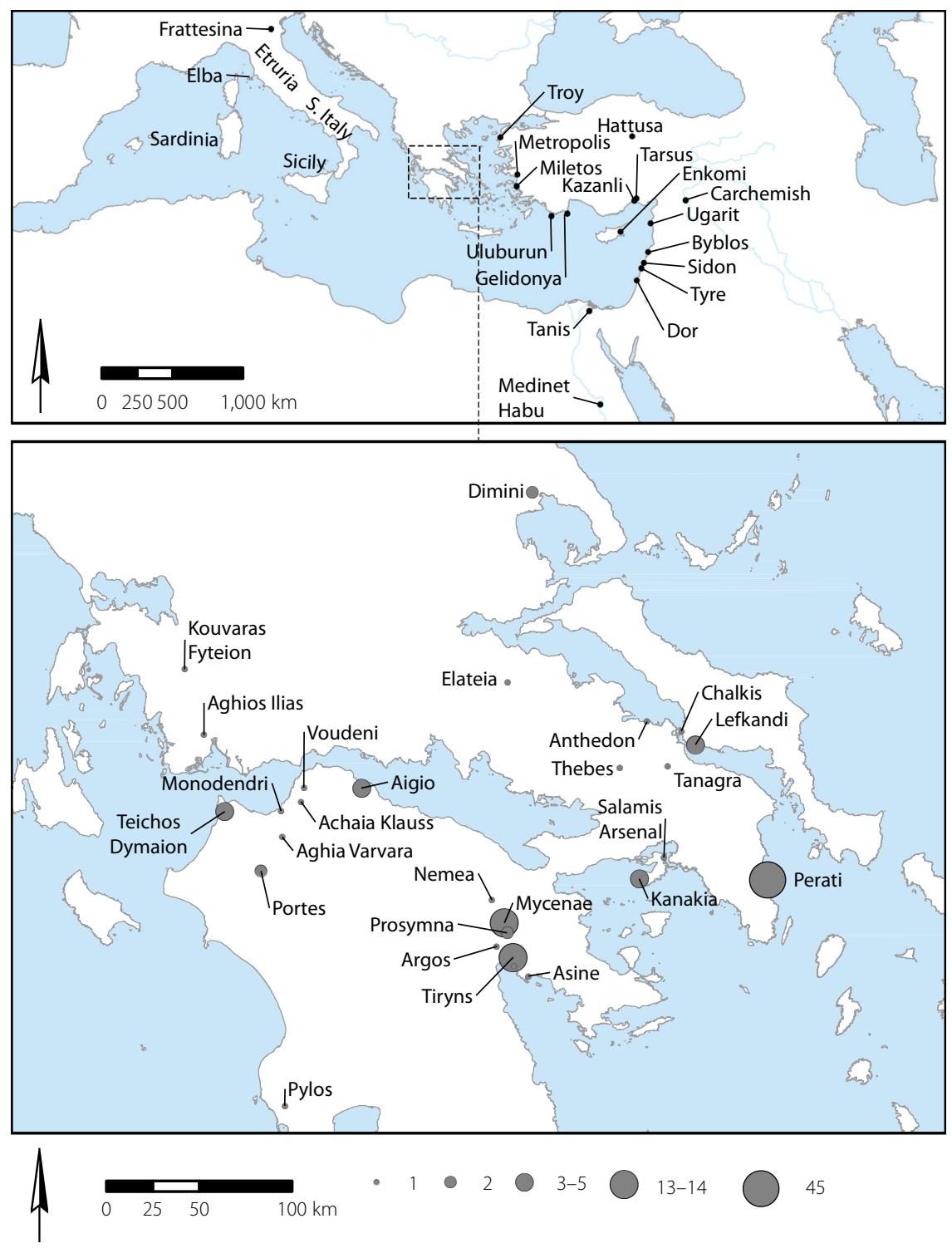

MAP 17. Mediterranean sites mentioned in the text (top) and imports to LH IIIC contexts in the Aegean (bottom) (import data from Murray 2017, 92-93, table 2.3).

Mediterranean during the thirteenth century BCE, the twelfth-century aftermath saw a robust Cypriot copper trade; the local production of Mycenaean or Mycenaeanizing (LH IIIC) pottery in Cyprus, the Levant, Italy, Sicily, and Sardinia; and the rise of Levantine (later lumped together by Herodotus as "Phoenician") city-states, 
out of which Tyre would eventually emerge as perhaps the greatest driver of longdistance ventures yet known (see map 17). The rearrangement of trade patterns that followed the decline of palace-centered states in the eastern Mediterranean at the same time spurred significant changes toward a more distributed economy. Meanwhile, changes in central Mediterranean societies led to the solidification of sustained and society-changing ties between east and west.

\section{Societal Reorientations in Greece and the Eastern Mediterranean}

Central Greece is by no means unique in the eastern Mediterranean in terms of its pattern of decentralization after 1200 BCE. The restructuring of settlement and social organization did not result in a collapse of interactions but rather in a reconfiguration of the networks through which they operated. Geographically, routes and pathways remained rather consistent, since favorable sea routes do not vary much over time and maritime technology did not experience any great shifts between the thirteenth and eleventh centuries BCE (Wachsmann 1998, 176; Sauvage 2012). It was rather a pattern of political decentralization in certain parts of the Aegean, Anatolia, Cyprus, the Levant, and Egypt that led to the development of more distributed, frequent, and varied types of interaction, ranging from the rise of merchant classes to population movements (Sherratt and Sherratt 1991, 1993; Iacovou 2005; Yasur-Landau 2010; Broodbank 2013).

Central Greece, especially in the regions surrounding the Euboean Gulf, enjoyed a sort of privileged status, as other regions, such as Crete, seem to have experienced depopulation and a certain attitude of fearfulness, with settlements shifting to defensible locations that were difficult to access (Nowicki 2000; Wallace 2010, 60-61; 2011, 59-60). Achaia in the northwest Peloponnese experienced relatively little settlement reorientation; it also seems to have been looking westward, given the large amount of LH IIIC Achaian pottery that has been found in southern Italy (Fisher 1988; Benzi and Graziadio 1996, 126; Papadopoulos 2001, 444-48; Arena 2015; Jung, Mommsen, and Picciarelli 2015). This suggests that the Corinthian Gulf was another major conduit, which should come as no surprise, given the importance of Corinth's later activity in the central Mediterranean. As discussed above, there was no palace in Achaia, and so no palatial collapse, leaving networks established earlier in the Mycenaean period to continue developing virtually uninterrupted. By contrast, Messenia seems to have experienced dramatic depopulation, while Laconia, Arcadia, and the Argolid experienced some continuity, though these areas did so in the context of political reorganization (Demakopoulou 2007; Galaty et al. 2015). The northern Aegean is more variable, clearly tied in to land routes to the wider Balkans and continental Europe, at least partly owing to its excellent metal resources (Morris 2009/2010).

The Cyclades and Dodecanese follow their own patterns in the Postpalatial period, with marked continuity from LH IIIB to LH IIIC, and in some cases even thriving in LH IIIC (Barnes 2016; Vlachopoulos and Charalambidou 2020). 
Fortified settlements in the Cyclades at Koukounaries on Paros, Grotta on Naxos, and Xombourgo on Tinos suggest that the Mycenaean maritime worlds maintained vibrant and sometimes violent connections in this part of the Aegean well into the Postpalatial period (Kourou 2002; Lambrinoudakis and PhilaniotouHadjianastasiou 2001; Schilardi 2016). These areas, like several parts of central Greece, are best considered nonpalatial zones in LH IIIB that seem actually to undergo an intensification of social complexity in the Postpalatial period, as do other areas connected to, but not part of, clearly palatial zones.

Looking beyond the Aegean to the archaeological record of imports and exports to and from Greece, there is a fair amount of consistency from LH IIIB to LH IIIC, though certain differences are telling (compare maps 13 and 17). Exports of Greek decorated pottery follow similar patterns in western Anatolia, southern Italy, Sardinia, and Cyprus, with a reduced presence in Syro-Palestine and an almost complete absence in Egypt (Murray 2017, 194). In many places, Mycenaean imports seem to be replaced eventually by local production. Imports to Greece maintain a wide distribution as well, although overall quantities decline (Murray $2017,118)$. If the palaces are removed from the equation, however, the quantity and distribution of imports actually increase.

A series of political upheavals in the eastern Mediterranean also affected social and economic conditions in central Greece. The downfall of the Hittite kingdom caused a major restructuring of the political landscape in Anatolia. Several sites along the Aegean coast maintained connections with the broader Aegean area, as can be seen in the presence of mostly locally manufactured LH IIIC pottery from Troy, Bademgedeği Tepe and Yeniköy (both near Metropolis), Miletos, Tarsus, and Kazanli (see map 17) (Mountjoy 2006, 107). Locally produced LH IIIC pottery was widely dispersed at a variety of sites. This may suggest a decentralization of trading activities and perhaps more mobile craftspeople, and hence that local production was more common than imports. This interpretation of new networks forming, rather than a mass migration from the Greek mainland, is also consistent with the mortuary evidence from this area, which points to new modes of exchange and sociopolitical change rather than to mass migrations (Georgiadis 2009). Communities along the Aegean and Mediterranean coasts of Turkey were now relatively independent. Significantly, sites that experienced the greatest continuity from the preceding Hittite period seem to have experienced the least integration into the new networks forming in the eastern Mediterranean. This was particularly true of Carchemish, where a Hittite dynasty was maintained that developed into a trading center and the capital of a significant Neo-Hittite kingdom in the Iron Age (Aro 2013). The new orientations of western Anatolia may provide context for the muchdebated formations of "Ionian" identity in the region (Mac Sweeney 2016; see further in chapter 5, pp. 187-89).

Cyprus is perhaps the most heavily researched example of Mycenaean activity abroad, which certainly affected aspects of social organization (Knapp and 
Manning 2016, 132-34). The period covered in this chapter (ca. 1200-1050 BCE) straddles the Protohistoric Bronze Age and Earliest Iron Age in Cyprus (1250-950 BCE). ${ }^{9}$ Major sociopolitical changes took place during this time, largely in relation to the wider eastern Mediterranean context. The question of Mycenaean colonization following the collapse of the palaces is highly controversial, although influence and contact is undeniable (Knapp 2008, 286-90). The larger issue is the role of metals and the general pattern of destabilization. The Late Bronze Age political landscape of Cyprus seems to involve elites at regional centers competing for power and control, while the Early Iron Age trends gradually toward ruling lines controlled by particular individuals or groups, which is also the case in later periods (Janes 2010, 135). That said, arguments have also been made for centralized control of the island, based at Enkomi, in the Protohistoric Bronze Age. Whatever the case may be, Late Bronze Age systems were disrupted significantly by (1) the destruction of Ugarit (ca. 1185 BCE), which destabilized Enkomi, and (2) a marked increase in Aegean presence. This destabilization paved the way for new groups and new practices of interaction to emerge, and it would have also led to the reconfiguration of off-island networks, which were reflected in the increased presence of Aegean and Levantine material and in the proliferation of Cypriot copper in the central Mediterranean (Lo Schiavo 2012).

The apparent growth of entrepreneurial trade at the end of the Bronze Age undermined palatial economies on the Levantine coast, most famously in the case of Ugarit, which was destroyed in 1185 BCE (Routledge and McGeough 2009, 29). Documents from merchants' houses in Ugarit suggest that a merchant class operated largely independently of the state and would have been able to continue with business more or less as usual in its absence, though with some necessary adjustments (Liverani 1987, 69-70; Snodgrass 1989, 25; Murray 2017, 257). In the aftermath, other areas of the Levantine coast rose to greater prominence and eventually came to dominate eastern Mediterranean trade by capitalizing on opportunities left in the wake of Ugarit, Hatti, and Egypt (Bell 2009). Mycenaean involvement in the Levant is evident in the form of painted pottery, although, as in Cyprus, the nature of the interactions evidenced by the presence of material culture is uncertain, with interpretations ranging from colonization to trade to stylistic influence (Yasur-Landau 2010).

Turning to Egypt, the Postpalatial Aegean overlaps chronologically with the end of the New Kingdom and Third Intermediate periods. The "Sea Peoples" as a distinct entity are principally an Egyptian conception, although as a construct they have taken on a sort of life of their own (see, e.g., Oren 2000; Cline and O'Connor 2003; Cline 2014; Fischer and Bürge 2017; Kopanias 2017). The reliefs on the mortuary

9. According to Knapp's $(2008,133)$ chronology, this period begins with the Protohistoric Bronze Age 3 period (1250-1100), which corresponds to the Late Cypriot IIC Late to Late Cypriot IIIA ceramic periods used in the conventional chronology. The Earliest Iron Age (1100-950) corresponds to the Late Cypriot IIIB period (ca. 1100-1050) and the Cypro-Geometric I period (ca. 1050-950) (Janes 2010, 129). 
temple of Rameses III (r. 1186-1155 BCE) at Medinet Habu already suggest insecurity, which the ruler attempted to capitalize on through self-aggrandizement. These events are part of a wider pattern of destabilization in Egypt, which might be traced back as far as the end of the 66-year reign of Rameses II in 1213 BCE. Six different kings ruled in the span of the 29 years that separate Rameses II and Rameses III. Rameses III's rule was by no means a period of stability either. During this period, the Egyptian empire in western Asia was lost, internal problems were rampant, and foreign invasions were increasing concerns. Economic instability built until civil war erupted, resulting in the division of Egypt and the end of the New Kingdom and the beginning of the Third Intermediate period, which coincides roughly with the end of the Postpalatial Bronze Age in the Aegean. The twenty-first dynasty began with the reign of Smendes (1069-1043), who ruled from Tanis in the Delta (Bard 2008, 216, 265). By the time the Tale of Wenamun was recorded (likely during the reign of Smendes), Egypt's influence in the eastern Mediterranean had waned considerably. Wenamun, a messenger of the king, was robbed, waylaid, and made to wait months for an audience during the course of his mission to procure cedar. His recorded stops at Dor, Sidon, Tyre, Byblos, and Cyprus, illustrate the increasingly diffuse nature of connectivity in the eastern Mediterranean, as power relations had shifted between participants in exchanges. ${ }^{10}$

\section{Shifting Networks in the Central Mediterranean}

Engagement between the central and eastern Mediterranean is well documented through imported and imitated Mycenaean pottery in Italy, Sardinia, and Sicily from at least the LH I period (Vagnetti 1999; van Wijngaarden 2002, 2016; Jones et al. 2014), as are connections between Cyprus and Sardinia in the form of Cypriot oxhide ingots (Stos-Gale and Gale 1992; Lo Schiavo 2012). There is also an abundance of central Mediterranean (especially Adriatic) material found in the eastern Mediterranean dating to the thirteenth and twelfth centuries BCE-most notably in the form of impasto-style, handmade burnished ware (so-called barbarian ware), Sardinian pottery, urnfield bronzes, and Tiryns-type amber beads, which were also from the Adriatic (Broodbank 2013, 463). While some of these contacts seem to have been sustained over time (for example, Mycenaean connections to southern Italy) the frequency and the multicultural scale of interaction reach new heights at the end of the second millennium.

These interactions have been studied mainly in terms of the presence of Mycenaean or Mycenaeanizing pottery, the known quantity of which has been rising steadily over the last decades. Taylour (1958) recorded 17 sites and, with ever growing datasets, the number has risen to at least 78 (Vagnetti 1999, 156-61; see also Papadopoulos 2001, 440-41; Blake 2008). Smith (1987) has separated the LH IIIC material from the rest, which shows a pattern of wider dispersal than in

10. For a longer account of the Tale of Wenamun and its significance, see Broodbank 2013, 445-49. 
previous periods. Besides imports, beginning around 1200 we see major changes in the societies of peninsular Italy, on both the Adriatic and Tyrrhenian coasts. On the Adriatic coast, a settlement on the Po appeared at Frattesina (Bietti Sestieri 2010, 186; see also Pearce 2007). In addition to imports of Aegean and Cypriot provenience, Frattesina was linked into more northerly networks supplying amber and metals, and to Etruria across the Apennines (Bietti Sestieri 1997; Vianello 2005, 91-93). In Etruria, too, metals seem to have been the main attractor, and exploitation of the region's ores (copper, silver, lead, antimony) intensified in the twelfth century (Bietti Sestieri 1997). The stretch of Etruria between the Arno and Ombrone rivers was remarkably well endowed, leading to the later regional referents Colline Metallifera and Etruria Mineraria. The region would become even more significant when the rich iron sources of the nearby island of Elba began to be exploited (see chapter 5, p. 174).

Southern Italy and Sicily exhibit by far the most Mycenaean interaction. While LH IIIC pottery found here probably comes from a variety of locations across the late Mycenaean world, the most common forms seem to be from Achaia, though relatively few provenience studies have been conducted (Fisher 1988; Vianello 2005, 9-10; Jones et al. 2014; Jung, Mommsen, and Picciarelli 2015). Nevertheless, this wide dispersal of LH IIIC material and styles speaks to an increasingly connected Mediterranean and belies any notions of Aegean isolationism or stagnation following the disappearance of the palaces.

Finally, Sardinia requires some additional attention as a rather more enigmatic entity at this time. There are marked rises in Cypriot activity on the island, as well as Aegean interventions, though the nature of these is not clear (Russell 2010, 114; Lo Schiavo 2012). Cypriot influence appears mainly in the form of metals and metalworking implements, not least in the preponderance of oxhide ingots. Aegean influence, as usual, is in ceramics. Sardinia was clearly valued for its copper resources, though the extent to which Sardinians were engaged in external trade before Cypriot involvement is difficult to say. It seems that, in this case, eastern interest sparked the formation of more local networks, which involved the wider Tyrrhenian Sea.

The ore deposits of Cyprus, Sardinia, and Italy attracted increasing attention from afar during the late second millennium BCE, which prefigured later, even more intensive exploitation. This trend is not necessarily new-earlier Mycenaeans certainly had a strong interest in Cyprus and Anatolia and at the very least dabbled in the central Mediterranean (van Wijngaarden 2002). Minimalist interpretations, however, have generally prevailed over ideas of "precolonization" (cf. Popham 1994; Blake 2008). As usual, the answer probably lies somewhere in between. There is a strong correlation between find locations of Mycenaean materials (especially from Achaia) and later Greek settlement in Italy and Sicily (Papadopoulos 2001, 441-48). The implication is that later Greeks were interested in these areas for the same reasons Mycenaeans were: metals. The quest for 
metals was nothing new in the Postpalatial period, and it has long been noted as a motivating factor for Mycenaean seafarers. Indeed, this is another arena in which the Early and Postpalatial Mycenaean world run parallel, while palatial emphasis on particularly eastern imports is more of an outlier. What is new is the context of this quest for metals. It is not until the LH IIIC period that Tyrrhenian, Adriatic, and eastern Mediterranean networks open up in such a way as to allow sustained interaction in multiple directions. The growth of regional networks in the central Mediterranean and the freeing of eastern Mediterranean networks from palatial constraints allowed new, decentralized systems to be formed, which is evident in the case of hybridizing Mycenaean and local production in Cyprus, the Levant, Italy, Sicily, and Sardinia. These patterns had already begun in LH IIIB, which suggests that interactions between crafting communities were already untethered from the palaces. In this way, the development of local networks made it easier for Mycenaeans and Cypriots to "plug in" to them, and it also created more diffuse distributions of material culture, perhaps through certain coastal entry points. This explains both how Greek-like material culture came to be produced in new locations and why in some cases it is found only as isolated examples. It also highlights the coastal nature of cross-cultural interaction during the period at hand, which is reflected as well in the regional settlement patterns of central Greece and elsewhere in the Mediterranean during this time of increasing maritime mobility.

\section{CONCLUSIONS: CENTRAL GREECE ON CENTER STAGE}

The patterns of settlement, production, and interactions in central Greece during the Postpalatial Bronze Age are part of a much larger process at work in the Late Bronze Age Mediterranean. Destabilization, mobility, and reorganization are key features, both for the Aegean and for the Mediterranean at large. The value of a multiscalar approach, however, lies in the capacity to move from the global to the local. In this way processes at work in the wider Mediterranean are also reflected in the local and regional networks of central Greece. New complex communities arose following the fall of the palaces, and new power relations developed, often through seaborne interactions. In these newly decentralized networks, political transformations occurred through particular individuals and groups that operated in relatively ill-defined, noninstitutionalized leadership systems. Societies of the Postpalatial period had less rigid but still politically significant systems of social hierarchy and regional organization. Manifestations of such reconstrued notions of society and polity are present at Kastro Volos, Kynos, Mitrou, Lefkandi, Perati, and Athens, among other places. At the same time, new regional interactions were negotiated, which resulted in the establishment of intercommunity ritual practices at Kalapodi. In stark contrast to the Palatial period, such regionally oriented group formation practices were disassociated with a single political power. Also divorced from palatial oversight, movement and interaction required new agency on the 
part of individuals; this translated into the emergence of community leaders who competed with rivals by land and by sea, probably taking part themselves in longdistance voyages. The movement of craftspeople (and probably also larger groups) also became widespread, as consumption of Mycenaean products in other parts of the Mediterranean continued, even in the face of stylistic regionalism.

The collapse of the palatial systems in parts of central Greece created new opportunities for the transformation of the political landscape, the reformulation of local and long-distance interactions, and the emergence of new forms of sociopolitical complexity. The northern and central Euboean Gulf went separate ways from the south, at least temporarily, and the Corinthian Gulf emerged as a significant conduit for connectivity to the west. This picture of fragmentation was part of a wider phenomenon of network shifts throughout the eastern Mediterranean, which eventually tapped expanding systems in the central Mediterranean. The result of this destabilization and reorganization was societies that were locally oriented in terms of territory but thrived on interaction at all scales-societies that were in regular conflict and collaboration with neighbors in their wider regional setting, yet had interests and influences that spanned significant distances. Despite the collapse of the palatial systems, the picture is far from one of societal collapse. In this chapter I have presented models and explanations for the transitions that characterized communities and networks in central Greece in the Postpalatial Bronze Age as certain communities reconstituted local and regional interactions and coopted overseas connections. The result was a more intricately intertwined Mediterranean world, which can be seen through a more variegated archaeology of Late Bronze Age societies. 